\title{
Negative Pressure Wound Therapy
}

National Cancer Institute

\section{Source}

National Cancer Institute. Negative Pressure Wound Therapy. NCI Thesaurus. Code C159891.

A wound dressing systems that continuously or intermittently applies subatmospheric pressure to the surface of a wound to draw out fluid and promote healing. 